quist, Dulk, Brandes und Wardenburg, nänlich dass der Brechweinstein bestehe aus 2 At. Antimonoxyd, 1 At. Kali, 2 At. Weinsteinsäure und 2 At. Wasser. Die experimentellen Resultate, welche die Analysen der drei letzt angeführten Chemiker ergeben, kommen dazu dem Resultate der Theorie weit näher, als die von $R$ ichardson erhaltenen.

Dieses belegt folgende Uebersicht:

\begin{tabular}{lccccc} 
& & & & \multicolumn{3}{c}{ Brandes u. } \\
& Theorie & Richardson & Wallquist & Dulk & Wardenb. \\
Antimonoxyd & 43,53 & 45,92 & 42,44 & 43,03 & 43,25 \\
Kali . . & 13,44 & 12,80 & 13,26 & 13,64 & 13,52 \\
Weinsteinsäure & 37,85 & 35,25 & 38,01 & 38,41 & 37,77 \\
Wasser. . & 5,13 & 4,84 & 5,14 & 5,99 & 5,24 \\
\cline { 2 - 7 } & .100. & $98,81$. & $99,45$. & $101,02$. & $99,78$.
\end{tabular}

In den beiden angeführten ausländischen Journalen hat man nicht für nöthig erachtet, diese früheren Arbeiten mit einem Worte zu erwähnen.

B r.

\title{
Ueber die Zersetzung des kohlensauren Kalks durch Hitze;
}

\author{
von \\ Gay-Lussac.
}

(Annales de Chem, et de Phys, LXIII. 219.)

Man hat schon seit geraumer Zeit behauplet, dass der Kalk bei Gegenwart von Wasser leichter ätzend sich brennen lasse, als ohne dasselbe, und die Kalkbrenner sind auch meist dieser Ansicht zugelban. Dumas glaubt, dass dieser Einfluss des Wassers auf zwei verschiedene Weisen sich erklären lasse. Entweder nimmt dasselbe, was jedoch nur auf kurze Zeit seyn kann, die Stelle der Kollensäure im kohlensauren Kalk ein, da Kalkhydrat schon bei Rothglüh- 
hitze zersetzt wird; oder das Wasser wird durch die als Brennmaterial angewandte Kohle zersetżt, es bilden sich verschiedene Gase und darunter auch Kohlenwasserstoffgas, welches die Kohlensäure des kohlens. Kalks zu Koblenoxydgas reducirt und dadurch deren leichtere Abscheidung bewirkt.

Die erste dieser beiden Erklärungen ist aber aus dem Grunde nicht zulässig, weil Kalkhydrat schon bei einer Temp. sich zersetzt, die weit niedriger ist, als die, bei welcher der kohlensaure Kalk unter Mitwirkung des Wasserdanpfs seine Kohlensäure verliert. Die zweite Erklärung dürfte nicht auf die Umstände anwendbar seyn, unter welchen die Verbrennung in den Kalköfen stalt findet. Ich werde mich also nicht dabei aufhalten, sondern sogleich meine Versuche mittheilen, woraus sich, meiner Ansicht nach, der Einfluss des Wassers beim Kalkbrennen ergiebt.

Eine mit Marmorstiicken gefüllle Porcellanröhre wurde über einem Ofen angebracht, dessen Temperalur leicht regulirt werden konnte. Das eine Ende der Röhre wurde mit einer Retorte verbunden, die Wasser enthielt, das andere Ende mit einer Glasröhre, um die Kohlensäure zu sammlen. Die Porzellanröhre wurde bis zu dem Grade erhitzt, wobei die Kohlensäure aus dem Marmor ausgetrieben wird, dann aber die Thür des Aschenfalls verschlossen, wodurch die Hitze zur Dunkelrothgluth herabsank und keine-Kohlensäure sich mehr entband. Jetzt wurde das Wasser in der Retorte zum Sieden erhitzt, und so wie die Wasserdämpfe in die Porcellanröhre gelangten und den Marmor berührten, fing die Entwicklung der Kohlensäure in reichlicher Menge wieder an. So wie man die Dampfbildung unterbrach, hörte die Kohlensäureentwicklung augenblicklich auf und erschien erst wieder mit einer neuen Einströmung von Wasserdampf.

Es scheint hiernach erwiesen; dass der Wasserdampf die. Zersetzung des koblens. Kalks durch die Hitze begünstigt, 
und dass diese Zersetzung dadurch bei einer niedrigeren Temp. statt findet, als gewöhnlich erforderlich ist.

Die Wirkung des Wassers scheint mir aber in diesem Fall eine rein mechanische zu seyn. Ist die Temperatur bis zur Zersetzung des kohlens. Kalks gediehen; so bildet sich um ihn eine Atmosphäre von Koblensäure, welche auf die mit dem Kalk verbunden bleibende Säure drückt, so dass letzlere zu ihrer Entbindung den Druck dieser Atmosphäre überwinden muss, was nur geschehen kann, wenn man entweder die Temperatur noch mehr erhölhet, oder wenn man die kohlensaure Atmosphüre beseiligt und einen luftleeren Raum herstelit, oder endlich, indem man diese Atmosphäre durch Wasserdampf oder irgend eine andere elastische Flüssigkeit, z. B. gewöhnliche Luft, ersetzt.

Diese Erklärung wird durch folgenden Versuch bestätigt. Kohlensaurer Kalk wurde in einer Porzellanröhre einer et was niedrigeren Temperatur ausgesetzt, als die ist, wobei er anfängt sich zu zersetzen, und dann wurde in die Röhre ein Strom atmosphärischer Luft geleitet. Sogleich fing die Kohlensäureentbindung an und dauerte so lange als der Luftstrom anhielt, hörte aber mit demselben auf und begann wieder mit Herstellung desselben.

Es. scheint mir also erwiesen, dass der Einfluss des Wasserdampfs beim Brennen des Kalks darauf sich beschränkt, einen luftleeren Raum für die Kohlensäure hervorzubringen und zu verhindern, dass die freigewordene Säure auf die mit dem Kalk verbunden gebliebene'drückt. Bei Gegenwart von Wasserdampf ist zwar eine geringere Temp. zum Austreiben der Koblensäure erforderlich, doch muss man die Wichtigkeit seines Einflusses nicht überschätzen. In den Kalksteinen befindet sich das Wasser mechanisch zwischen deren kleinsten Theilchen, und mit Ausnahme von etwas Wasser, welches in der Mitte von Stücken zurückbleibt, die 
zu gross sind, als dass die Hitze schnell eindringen und dasselbe verflüchtigen kann, muss der grösste Theil des Wassers ohne nützliches Fesultat und sogar mit Verlust an Brennmaterial sich verflüchtigen, noch ehe der Kalkstein die zu seiner Zersetzung geeignete Temperatur erlangt hat.

Der Wasserdampf begïnstigt allerdings das Brennen des Kalks, doch bleibe ich in Zweifel, ob er wirklich Vortheile. darbieten kann, weil zwischen der Temp., wobei sich der kohlens. Kalk für sich schon zerselzt und derjenigen, wobei er mit Hülfe des Wasserdampfs zersetzt wird, kein grosser Unterschied statt findet. Wenn ïbrigens der Wasserdampf beim Brennen des Kalks bloss eine mechanische Wirkung ausübt, gerade so wie die atmosphärische.Luft, so begreift man nicht, welchen grossen Vortheil er vor dem gasförmigen Strome der Verbrennungsprodukte, welcher den Kalk im Ofen unaufhörlich durchstreicht, voraushaben kann.

Die Thatsache, dass kohlens. Kalk durch Zutritt von Wasser, oder vielmehr in luftverdïnntem Raume leichter sich zersełzt, ist keine eigenthümliche; vielmehr lässt sich. die Regel aufsiellen, dass wenn bei einer Zerselzung durch. die Hitze oder ein chemisches Agens, eines oder melre gasförmige Elemente abgeschieden werden, die Zersetzung dadurch sich beschleunigen lässt, dass man, den Körper im luftleeren Raume erhält, oder die sich entbindenden elastischen. Flüssigkeilen verhindert, auf ihn zu drücken. Und umgekehrt läsș sich die Zersetzung verzögern oder sogar ganz verhindern, wenn man um den Körper einen hinreichenden Druck nit einer elastischen Flüssigkeit von derselben Art wie die auszutreibende unterbält. Bei dem merkwürdigen Versuche Hall's wird auf diese Weise bei einer sehr hohen Temp. der kohlens. Kalk mit Hülfe des Drucks von kohlensaurem Gas in Fluss gebracht. 